\title{
Reassessing blood acetylcholinesterase in dementia
}

Alzheimer's dementia (AD) and Parkinson's disease dementia (PDD) have grown into prevalent public health issues not only in developed countries but also in rural areas within underdeveloped regions. It is a particular medical and social challenge to find efficient biomarkers to screen the potential patients at low cost, and ideally predict the clinical progress. Cholinergic system has attracted substantial interest in Alzheimer's disease research over the past several decades. Cholinesterase inhibitor was the first category of medication that clinically proven to be effective in symptomatic treatment of Alzheimer's disease in late 90s. Despite numerous basic research and clinical trials over the past decade, no other drug categories had been translated into successful clinical application. Therefore, cholinesterase remains the key molecule in Alzheimer's disease research.

A key issue is whether blood acetylcholinesterase (AChE) activity be a reliable surrogate for Alzheimer's disease and other dementia. Several previous studies have measured the red blood cell (RBC) and plasma AChE activity in cognitive normal subjects and AD patients. However, these studies yield inconsistent results. ${ }^{[1-5]}$ The study by Bawaskar et al. measured AChE activity in RBC, plasma and whole blood samples from familial dementia patients, the patients' close relatives who are not demented, PDD patients, their relatives who are not motor impaired or demented, and normal control subject groups. ${ }^{[6]}$ In addition, the authors include a group of farmers exposed to environmental and occupational cholinesterase inhibitors (pesticide) as a positive control. In each group, RBC AChE activity is 2-3 times higher than plasma AChE. The whole blood AChE activity is determined by the average of RBC and plasma AChE. Using the data from their paper, ${ }^{[6]}$ I did a linear regression of whole blood AChE vs the average value of RBC and plasma AChE, showing a nice fit $(y=1.08 x+375, r=0.959$, where $y$ is the measured whole blood AChE activity, $x$

\begin{tabular}{|l|l|}
\hline \multicolumn{2}{|c|}{ Access this article online } \\
\hline Quick Response Code: & Website: \\
\hline & www.ruralneuropractice.com \\
\cline { 2 - 2 } & \\
\hline
\end{tabular}

equals the numerical average of RBC and plasma AChE). Thus, I will only analyze RBC and plasma AChE without further commenting on the whole blood AChE as it is not an independent factor.

This study showed that RBC AChE activity was reduced in familial dementia and their nondemented relatives. This is in agreement with a previous study ${ }^{[1]}$ However, other previous studies ${ }^{[2,3]}$ did not show RBC AChE reduction in $\mathrm{AD}$. A limitation of the current study is that the exact diagnosis and categories of familial dementia were not confirmed by genetic study or advanced imaging study due to socioeconomic restriction. Hence, the sensitivity, specificity, and the validity of AChE activity as a biomarker in this population could not be established. The authors are encouraged to complete this measurement in follow-up study through collaboration with international philanthropic organizations to overcome the socioeconomic hurdles. It is interesting to see RBC AChE reduced in nondemented relatives. Assuming this group of familial dementia reasonably represents familial $\mathrm{AD}$, it suggests that $\mathrm{AChE}$ reduction precedes the onset of dementia and may be determined by $\mathrm{AD}$ genetic factors. Although this study failed to show any statistically significant change of plasma AChE in familial dementia, the plasma AChE activity has a slight up trend in familial dementia patients and their relatives. Several previous studies had shown a significant upregulation of plasma $\mathrm{AChE}$ activity in $\mathrm{AD}$ patients. ${ }^{[2,4,5]}$ Taken this study together with previous studies, AD patients show a downregulation (or no change) in RBC AChE activity, but an upregulation (or no change) in plasma AChE. The inverse relationship between RBC AChE and plasma AChE seems apparent but needs clarification in future studies.

Since the lack of intrinsic scientific link between PDD and acetylcholine, there are few studies addressing AChE activity in PDD. This current study showed that both RBC and plasma AChE activity increased in PDD patients. Again, the limitation is primarily the lack of validation with advanced diagnostic approach. If this relation with PDD holds true, it would be interesting to explore the role of $\mathrm{AChE}$ in $\mathrm{PD}$ pathogenesis and therapy. In general, additional number of patients and affirmative diagnostic parameter would help improve 
the study, should the authors decide to continue follow up this cohort aiming to establish a reliable biomarker.

\section{Pengcheng Han}

Dignity Health St. Joseph Hospital and Medical Center,

Phoenix, Arizona, USA

Address for correspondence:

Dr. Pengcheng Han,

Dignity Health St. Joseph Hospital and Medical Center, 350 West Thomas Road, Phoenix, Arizona - 85013, USA. E-mail: pengcheng.Han@dignityhealth.org

\section{References}

1. Chipperfield B, Newman PM, Moyes IC. Decreased erythrocyte cholinesterase activity in dementia. Lancet 1981;2:199.
2. Atack JR, Perry EK, Perry RH, Wilson ID, Bober MJ, Blessed G, et al. Blood acetyl- and butyrylcholinesterases in senile dementia of Alzheimer type. J Neurol Sci 1985;70:1-12.

3. Sirviö J, Kutvonen R, Soininen H, Hartikainen P, Riekkinen PJ. Cholinesterases in the cerebrospinal fluid, plasma, and erythrocytes of patients with Alzheimer's disease. J Neural Transm 1989;75:119-27.

4. Perry RH, Wilson ID, Bober MJ, Atack J, Blessed G, Tomlinson BE, et al. Plasma and erythrocyte acetylcholinesterase in senile dementia of Alzheimer type. Lancet 1982;1:174-5.

5. García-Ayllón MS, Riba-Llena I, Serra-Basante C, Alom J, Boopathy R, Sáez-Valero J. Altered levels of acetylcholinesterase in Alzheimer plasma. PLoS One 2010;5:e8701.

6. Bawaskar HS, Bawaskar PH, Bawaskar PH. RBC acetyl cholinesterase: A poor man's early diagnostic biomarker for familial Alzheimer's and Parkinson's disease dementia. J Neurosci Rural Pract 2015;6:35-40.

How to cite this article: Han P. Reassessing blood acetylcholinesterase in dementia. J Neurosci Rural Pract 2015;6:6-7.

Source of Support: Nil. Conflict of Interest: None declared.

Announcement

\section{iPhone App}

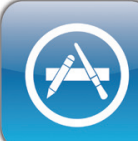

Download

iPhone, iPad application
A free application to browse and search the journal's content is now available for iPhone/iPad. The application provides "Table of Contents" of the latest issues, which are stored on the device for future offline browsing. Internet connection is required to access the back issues and search facility. The application is Compatible with iPhone, iPod touch, and iPad and Requires iOS 3.1 or later. The application can be downloaded from http://itunes.apple.com/us/app/medknow-journals/ $\mathrm{id} 458064375$ ? $\mathrm{s}=1 \& \mathrm{mt}=8$. For suggestions and comments do write back to us. 